\title{
Adsorption of Monobutyl Phthalate from Aqueous Phase onto Two Macroporous Anion-Exchange Resins
}

\author{
Zhengwen Xu, ${ }^{1,2}$ Yunlong Zhao, ${ }^{1,2}$ Jing Shi, ${ }^{3}$ Jiangang Lu,, \\ Ling Cheng, ${ }^{1,2}$ and Mindong Chen ${ }^{1,2}$ \\ ${ }^{1}$ Jiangsu Key Laboratory of Atmospheric Environment Monitoring and Pollution Control, \\ Nanjing University of Information Science and Technology, Nanjing 210044, China \\ ${ }^{2}$ School of Environmental Science \& Engineering, Nanjing University of Information Science and Technology, \\ Nanjing 210044, China \\ ${ }^{3}$ School of Sciences, China Pharmaceutical University, Nanjing 211198, China \\ Correspondence should be addressed to Zhengwen Xu; zhouxu3037@sina.com and Jing Shi; 347475315@qq.com
}

Received 19 November 2013; Accepted 13 December 2013; Published 8 January 2014

Academic Editor: Qingrui Zhang

Copyright (C) 2014 Zhengwen Xu et al. This is an open access article distributed under the Creative Commons Attribution License, which permits unrestricted use, distribution, and reproduction in any medium, provided the original work is properly cited.

As new emerging pollutants, phthalic acid monoesters (PAMs) pose potential ecological and human health risks. In the present study, adsorption performance of monobutyl phthalate (MBP) onto two macroporous base anion-exchange resins (D-201 and D301) was discussed. It was found that the adsorption isotherms were best fitted by the Langmuir equation while the adsorption kinetics were well described by pseudo-first-order model. Analyses of sorption isotherms and thermodynamics proved that the adsorption mechanisms for DBP onto D-201 were ion exchange. However, the obtained enthalpy values indicate that the sorption process of MBP onto D-301 is physical adsorption. The equilibrium adsorption capacities and adsorption rates of DBP on two different resins increased with the increasing temperature of the solution. D-301 exhibited a higher adsorption capacity of MBP than D-201. These results proved that D-301, as an effective sorbent, can be used to remove phthalic acid monoesters from aqueous solution.

\section{Introduction}

Water pollution by phthalic acid esters (PAEs) has attracted increasing attention in recent decades. They are widely used as plasticizers in the manufacture of polyvinyl chloride [1]. Phthalic acid monoesters (PAMs) as degradation products of PAEs or synthetic intermediates for the preparation of PAEs have attained more attention. They are mutagenic endocrine disrupting compounds, posing the adverse reproductive effects on humans and wildlife equal to PAEs. Some studies have shown that the hydrolytic breakdown products of some PAEs have higher toxicity than PAEs [2]. Recently, many PAMs have been detected in surface water, sea water, and landfill leachate [3]. Previous research proved that some PAMs have greater solubility than corresponding PAEs, especially for monomethyl phthalate (MMP, $3721 \mathrm{mg} / \mathrm{L}$ ), monobutyl phthalate (MBP, $409 \mathrm{mg} / \mathrm{L}$ ), and mono-ethylhexyl-phthalate (MEHP, $1.85 \mathrm{mg} / \mathrm{L}$ ). Thus, some polluted aquatic environment may contain high concentration of PAMs $[4,5]$. For instance, Jonsson found that, in landfill leachate, MBP appeared at a concentration of $2500 \mu \mathrm{g} / \mathrm{L}$ that was much higher than that of dibutyl phthalate (DBP) $(50 \mu \mathrm{g} / \mathrm{L})[6]$. Therefore, as a new type of organic pollutants, how to effectively remove PAMs from aqueous solution is an important issue.

Many previous studies have reported that PAMs can be removed from aqueous environment through different methods, such as activated sludge process [7] and adsorption $[8,9]$. In the active sludge process, PAMs can be further broken down to phthalic acid, benzoic acid, and finally carbon dioxide $[10,11]$. However, this process was reported to be relatively slow and is not expected to be an effective method, because of the toxicity of PAMs to microorganism $[12,13]$. Earlier research results indicated that PAMs can be adsorbed by chitosan, but the adsorption capability $(0.015 \mathrm{mg} / \mathrm{g})$ was too low to application in practice [10]. 
TABLE 1: Salient properties of polymeric adsorbents.

\begin{tabular}{|c|c|c|}
\hline & D201 & D301 \\
\hline BET surface area $\left(\mathrm{m}^{2} / \mathrm{g}\right)$ & 25.6 & 31.8 \\
\hline Particle size $(\mathrm{mm})$ & $0.4 \sim 0.7$ & $0.4 \sim 0.6$ \\
\hline Cross-link density (\%) & 8 & 8 \\
\hline Appearance & Ivory white & Ivory white \\
\hline $\begin{array}{l}\text { Functional groups } \\
\text { species }\end{array}$ & $\begin{array}{l}\text { Quaternary amine } \\
\left(-\mathrm{CHN}^{+}\left(\mathrm{CH}_{3}\right)_{3}\right)\end{array}$ & $\begin{array}{l}\text { Tertiary amine } \\
\left(-\mathrm{CH}_{2} \mathrm{~N}\left(\mathrm{CH}_{3}\right)_{2}\right)\end{array}$ \\
\hline $\begin{array}{l}\text { Amino content } \\
(\mathrm{m} \mathrm{mol} / \mathrm{g})\end{array}$ & 3.7 & 4.9 \\
\hline
\end{tabular}

The primary objective of the present study is to find a new method for effective removal of PAMs from aqueous solution. MBP is chosen as a representative target contaminant because of its widespread occurrence in aqueous environment. The adsorption performance of MBP onto a macroporous strongly basic anion exchanger D-201 and a macroporous weakly basic anion exchanger D-301 was investigated.

\section{Materials and Methods}

2.1. Materials. Sodium hydroxide, hydrochloric acid, phosphoric acid, ethanol, methanol, and monobutyl phthalate (MBP) were used in this study. All chemicals are of analytic grade and were purchased from Nanjing reagent station. D-201 and D-301 were provided by Hangzhou Zhengguang Resin Co. Ltd. (Zhejiang Province, China). Physicochemical properties of the sorbents used in this study are presented in Table 1.

2.2. Resin Pretreatment. Prior to use, all the resins were packed in column and first rinsed with DI (deionized), and then with 50 bed volumes (BV) of $1.0 \mathrm{~N} \mathrm{NaOH}$ followed by DI washing until neutral $\mathrm{pH}$ was achieved. After this, the column was subjected to acidic flushing by introducing $50 \mathrm{BV}$ of $1.0 \mathrm{~N}$ $\mathrm{HCl}$ and again DI flushing to neutral $\mathrm{pH}$. Finally, the resin was washed with ethanol using the same method and desiccated at $308 \mathrm{~K}$ for $24 \mathrm{~h}$ before use [14].

2.3. Sorption Experiments. Batch sorption tests were carried out in $100 \mathrm{~mL}$ glass bottles. To start the experiment, $0.050 \mathrm{~g}$ of sorbent was introduced into $50 \mathrm{~mL}$ solution containing a known concentration $(50,100,150,200,250$, and $300 \mathrm{mg} / \mathrm{L})$ of MBP. The flask then was transferred to a G24 model incubator shaker with thermostat (Jintan Medical Instrument Factory, Jiangsu Province, China) and shaken under $150 \mathrm{rpm}$ for $24 \mathrm{~h}$ at desired temperature $(288 \mathrm{~K}, 298 \mathrm{~K}$, and $313 \mathrm{~K})$ to ensure equilibrium of the adsorption process. A series of parallel kinetics experiments were carried out at different conditions: the concentration and volume of MBP solutions, mass of resins, agitated speed (DF-101B model stirrer, Nanjing Yuhua Instrument Co. Ltd., Jiangsu Province, China), and temperature (TH-10 model intelligence electrothermostatic water cabinet, Ningbo Tianheng instrument factory, Zhejiang Province, China) were $20 \mathrm{mg} / \mathrm{L}, 2000 \mathrm{~mL}, 1 \mathrm{~g}, 400 \mathrm{rpm}$, and $288 \mathrm{~K}, 298 \mathrm{~K}$, and $313 \mathrm{~K}$, respectively. With MBP sorption at different time intervals, $1 \mathrm{~mL}$ solution of MBP was extracted for detecting.

2.4. Analysis. Measurements of the BET surface area were based on $\mathrm{N}_{2}$ adsorption data from an Autosorb-IQ-AG-MP Sorptomatic apparatus (Quantachrome Instruments, USA).

Concentrations of MBP in the solution were analyzed by HPLC (Agilent, 1200, USA) equipped with a reverse phase column (Agilent, TC-C18, $3.19 \mathrm{~mm} \times 150 \mathrm{~mm}$ ) and a UV detector. The mobile phase was composed of $68 \%$ methanol and $32 \%$ purified water and the detective wavelength was $228 \mathrm{~nm}$ [15]. Prior to analysis, the phosphorous acid was used to adjust the sample solution to acidity [16] (about $\mathrm{pH}=4.0$ ).

The anion-exchange capacity of D201 and D301 was determined by the literature method [17].

The rate of MBP adsorption, $q_{t}(\mathrm{mg} / \mathrm{g})$, was calculated using the relation

$$
q_{t}=\frac{\left(C_{i}-C_{t}\right) V}{M}
$$

with $C_{i}(\mathrm{mg} / \mathrm{L})$ being the initial concentration of MBP, $C_{t}$ $(\mathrm{mg} / \mathrm{L})$ representing the concentration of time, $V(\mathrm{~L})$ being the volume of solution, and $M(\mathrm{~g})$ the mass of dry adsorbents $[10]$.

\section{Result and Discussion}

3.1. Characterization of Sorbent. Some important physicalchemical properties of D-201 and D-301 are present in Table 1. As can be seen from Table 1, the two exchangers have low surface area (less than $40 \mathrm{~m}^{2} / \mathrm{g}$ ) and a large number of functional groups. For the strongly basic anion-exchange resin D-201, it contains $3.7 \mathrm{mmol} / \mathrm{g}$ quaternary amine; for the weak base anion exchanger, the exchangeable capacity of D301 is $4.9 \mathrm{mmol} / \mathrm{g}$. These two adsorbents show a similar particle size and cross-link density.

3.2. Adsorption Isotherms. Adsorption isotherms of MBP onto D-201 and D-301 (in Figure 1) are represented by Langmuir model and Freundlich model [18]:

$$
\begin{gathered}
\frac{1}{q_{e}}=\frac{1}{K_{L} q_{m} C_{e}}+\frac{1}{q_{m}}, \\
q_{e}=K_{f} C_{e}^{1 / n}
\end{gathered}
$$

where $q_{e}(\mathrm{mg} / \mathrm{g})$ is the equilibrium adsorption capacity, $C_{e}$ $(\mathrm{mg} / \mathrm{L})$ represents the solute concentration in equilibrium, $K_{f}$ and $n$ are the Freundlich constants to be determined, $q_{m}$ $(\mathrm{mg} / \mathrm{g})$ is the maximal sorption capacity, and $K_{L}(\mathrm{~L} / \mathrm{mg})$ is a binding constant.

It can be observed from Figure 1 that the amounts adsorbed of MBP on D-201 and D-301 are increased with the increase of equilibrium concentrations, indicating the spontaneous process. Results in Table 2 show that the Langmuir model and the Freundlich model representing the MBP adsorption isotherms were different by the value of $R$ square $\left(R^{2}\right)$. The Langmuir model may be more reasonable 
TABLE 2: Adsorption isotherm parameters of D-201 and D-301.

\begin{tabular}{|c|c|c|c|c|c|c|c|}
\hline \multirow{2}{*}{ Adsorbent } & \multirow{2}{*}{$T / K$} & \multicolumn{3}{|c|}{ Langmuir } & \multicolumn{3}{|c|}{ Freundlich } \\
\hline & & $q_{m}(\mathrm{mg} / \mathrm{g})$ & $K_{L}(\mathrm{~L} / \mathrm{mg})$ & $R^{2}$ & $K_{F}$ & $n$ & $R^{2}$ \\
\hline \multirow{3}{*}{ D-201 } & 288 & 284.6 & 0.043 & 0.994 & 51.1 & 3.137 & 0.916 \\
\hline & 298 & 287.8 & 0.050 & 0.990 & 57.0 & 3.283 & 0.913 \\
\hline & 313 & 288.3 & 0.098 & 0.943 & 82.1 & 4.014 & 0.942 \\
\hline \multirow{3}{*}{ D-301 } & 288 & 388.9 & 0.088 & 0.987 & 84.7 & 3.159 & 0.887 \\
\hline & 298 & 390.7 & 0.107 & 0.987 & 98.7 & 3.462 & 0.901 \\
\hline & 313 & 400.0 & 0.128 & 0.998 & 123.5 & 4.043 & 0.943 \\
\hline
\end{tabular}

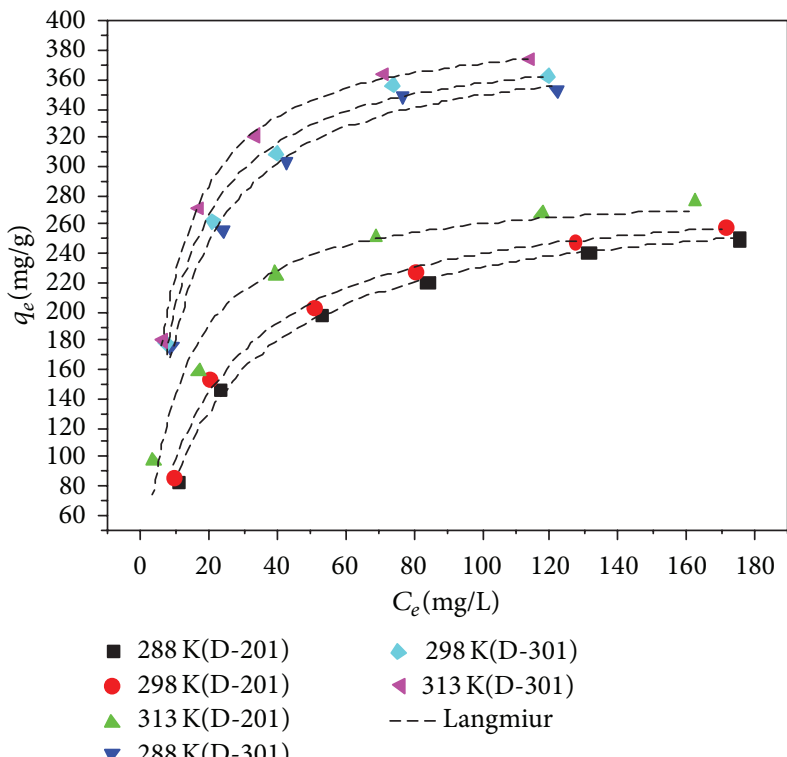

(a)

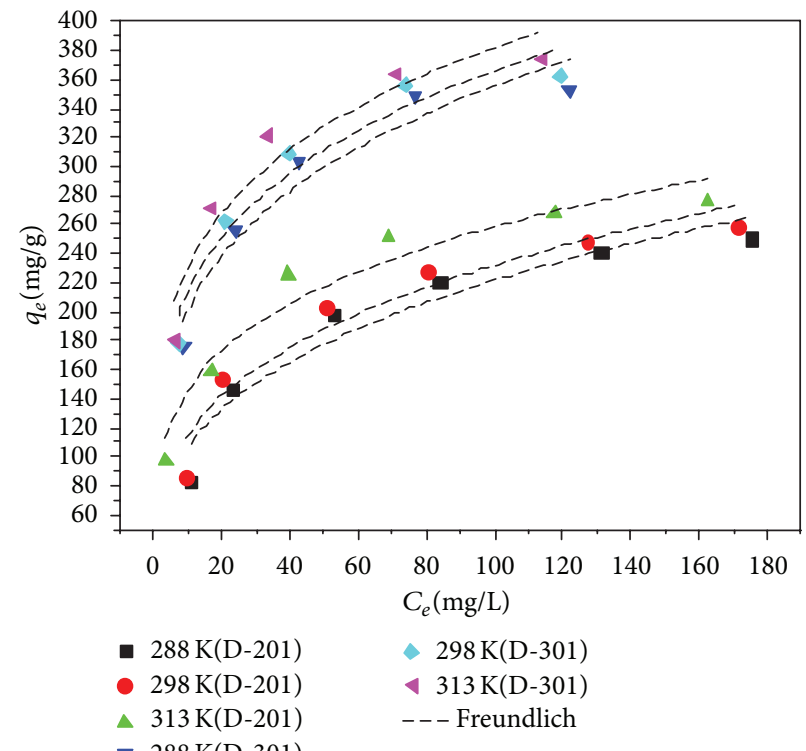

(b)

FIgURE 1: Equilibrium adsorption isotherms of MBP on D-201 and D-301. (a) Fitting by Langmuir equation. (b) Fitting by Freundlich equation.

than Freundlich model. $q_{m}$ values increased by the rise of temperature, which may also indicate that the adsorption of MBP onto D-201 or D-301 was an endothermic process. In other words, higher temperature is more favorable for MBP adsorption onto D-201 and D-301. This result indicated that the function groups of D-201 and D-301 play an important role in the removal process of MBP from aqueous solution. As shown in Figure 1 and Table 2, the maximum adsorption capacity of MBP on D-301 is much higher than that on D-201. The more excellent adsorption property of D-301 than D-201 may be attributed to its large number of functional groups. In addition, all the values of $n$, the Freundlich parameter, are greater than one, which means that the adsorption of MBP on the two sorbents is the optimal adsorption [19].

3.3. Thermodynamic Analysis. Thermodynamic parameters for the adsorption process can be calculated as

$$
\begin{gathered}
\Delta G=-R T \ln K_{L}, \\
\ln K_{L}=-\frac{\Delta H}{R T}+A, \\
\Delta G=\Delta H-T \Delta S,
\end{gathered}
$$

\begin{tabular}{|c|c|c|c|c|c|}
\hline \multirow{2}{*}{ Adsorbent } & \multirow{2}{*}{$\Delta H(\mathrm{~kJ} / \mathrm{mol})$} & \multicolumn{3}{|c|}{$\Delta G(\mathrm{~kJ} / \mathrm{mol})$} & \multirow{2}{*}{$\Delta S(\mathrm{~J} / \mathrm{mol})$} \\
\hline & & $288 \mathrm{~K}$ & $298 \mathrm{~K}$ & $313 \mathrm{~K}$ & \\
\hline D-201 & 25.32 & 7.72 & 7.11 & 6.19 & 61.11 \\
\hline D-301 & 11.12 & 5.78 & 5.59 & 5.32 & 18.54 \\
\hline
\end{tabular}

TABLE 3: Thermodynamic parameters of D-201 and D-301.

where $T$ is the absolute temperature in $\mathrm{K}$ and $K_{L}$ is the Langmuir adsorption constant. $R$ is the gas constant with a value of $8.314 \mathrm{~J} /(\mathrm{mol} / \mathrm{K})$, and $A$ is a constant $[20,21]$. The enthalpy change $\Delta H$ was determined by plotting $\ln K_{L}$ versus $1 / T$ (Figure 2). Thermodynamic parameters of MBP adsorption onto D-201 and D-301 are listed in Table 3.

Generally, the enthalpy change due to chemical adsorption $(>20 \mathrm{~kJ} / \mathrm{mol})$ is considerably larger than that due to physical adsorption $(<20 \mathrm{~kJ} / \mathrm{mol})$. The adsorption enthalpies in Table 3 suggest that the adsorption process of MBP on D-201 might be considered to be ion exchange in nature. However, the agreement of MBP adsorption enthalpy with values for physisorption ( 0 to $20 \mathrm{~kJ} / \mathrm{mol}$ ) indicates that MBP was adsorbed onto D-301 via physical adsorption. 
TABLE 4: Adsorption kinetic parameters of D-201 and D-301.

\begin{tabular}{lcccc}
\hline \multirow{2}{*}{ Temperature } & \multicolumn{2}{c}{ Pseudo-first-order kinetic model } & \multicolumn{2}{c}{ Pseudo-second-order kinetic model } \\
& $k_{1}(1 / \mathrm{min})$ & $R^{2}$ & $k_{2}(\mathrm{~g} / \mathrm{kg} \cdot \mathrm{min})$ & $R^{2}$ \\
\hline $\mathrm{D}-201$ & 0.016 & 0.996 & 185.5 & 0.979 \\
$\mathrm{D}-301$ & 0.016 & 0.998 & 189.4 & 0.990 \\
\hline
\end{tabular}

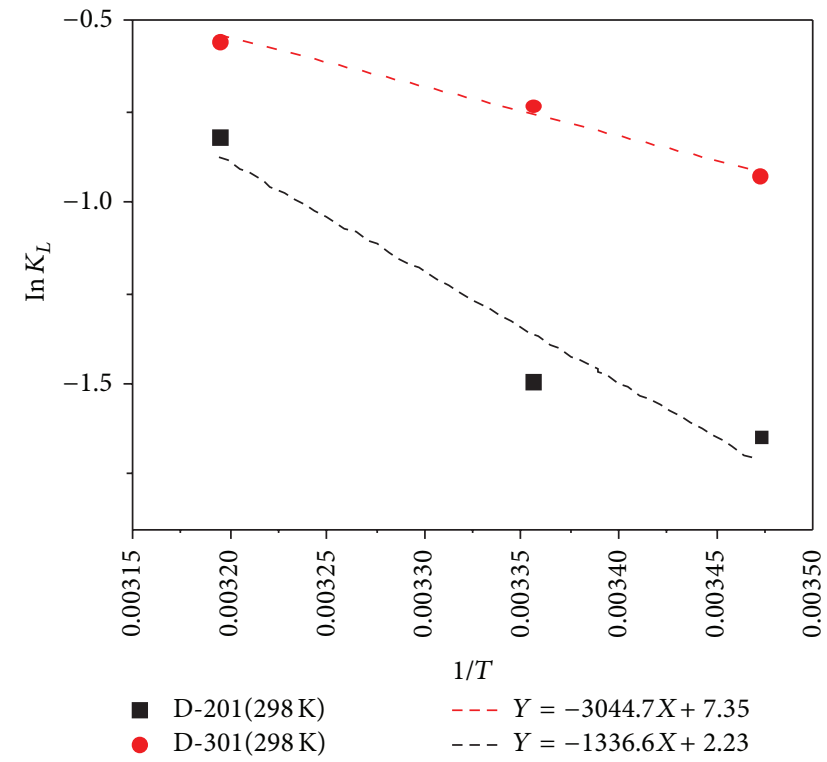

FIGURE 2: Van't Hoff plot for the adsorption of MBP onto D-201 and D-301.

The positive $\Delta S$ values in Table 3 imply that MBP adsorption onto D-201 and D-301 is entropy-driven process [22].

3.4. Adsorption Kinetic. Figure 3 shows sorption kinetics of MBP onto D-201 and D-301. It is clear that about $250 \mathrm{~min}$ was required to reach sorption equilibrium for the two adsorbents. Pseudo-first- and pseudo-second-order models were fitted to the kinetic data [23]:

$$
\begin{gathered}
\ln \left(q_{e}-q_{t}\right)=\ln q_{e}-k_{1} t, \\
\frac{1}{q_{t}}=\frac{1}{k_{2} q_{e}^{2} t}+\frac{1}{q_{e}},
\end{gathered}
$$

where $k_{1}$ and $k_{2}$ are the pseudo-first-order model and pseudo-second-order model constants to be determined. The kinetic parameters are determined and listed in Table 4.

From Table 4 we can see that the pseudo-first-order model gave a better representation of the data than the pseudo-second-order model. It is apparently clear that the values of the rate constant $k_{1}$ in Table 4 are similar to each adsorbent.

\section{Conclusion}

In summary, this work provides a new approach to remove $\mathrm{MBP}$ from an aqueous solution, using two macroporous

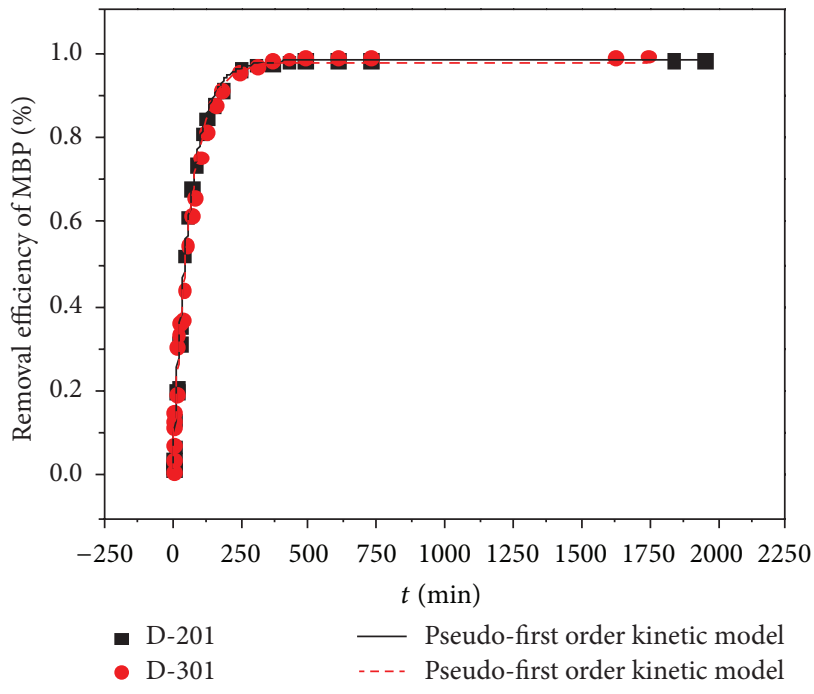

(a)

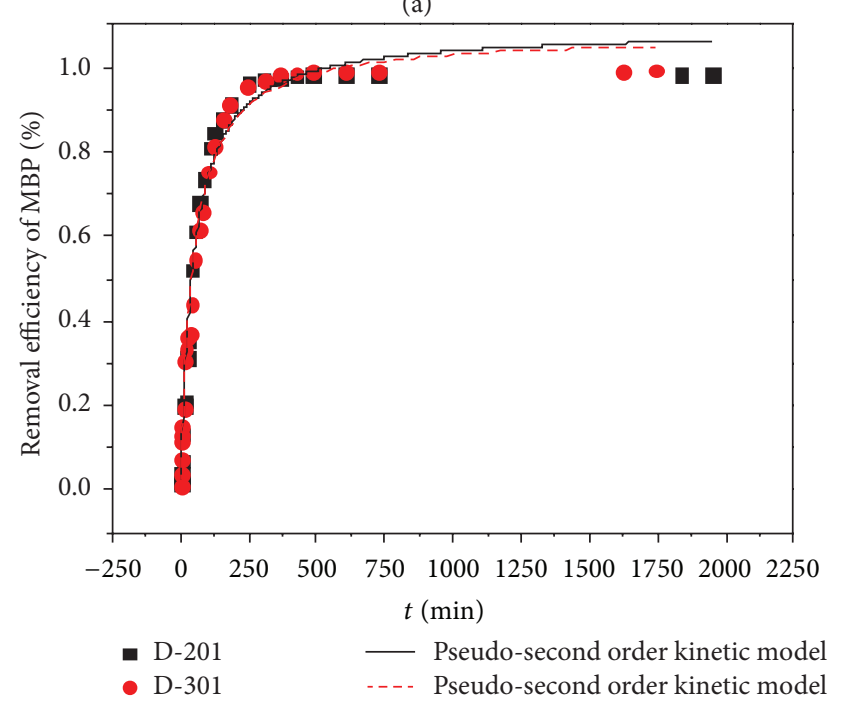

(b)

FIgure 3: Adsorption kinetics of MBP onto D-201 and D-301 at 298 K. (a) Fitting by Pseudo-first-order equation. (b) Fitting by Pseudo-second-order equation.

anion-exchange resins.The results reported herein demonstrate that the macroporous weakly basic anion exchanger D-301 was a highly efficient material for MBP removal. The satisfactory adsorption capability of D-301 displays its potential for PAMs removal in aqueous environment.

\section{Conflict of Interests}

The authors declare that there is no conflict of interests regarding the publication of this paper. 


\section{Acknowledgments}

The authors wish to thank the National Natural Science Foundation of China (Grant no. 21107050) and a project funded by the Priority Academic Program Development of Jiangsu Higher Education Institutions for supporting this study.

\section{References}

[1] X. W. Peng, L. J. Feng, and X. G. Li, "Pathway of diethyl phthalate photolysis in sea-water determined by gas chromatographymass spectrometry and compound-specific isotope analysis," Chemosphere, vol. 90, no. 2, pp. 220-226, 2013.

[2] C. K. Lim, S. Kim, D. S. Ko et al., "Differential cytotoxic effects of mono-(2-ethylhexyl) phthalate on blastomere-derived embryonic stem cells and differentiating neurons," Toxicology, vol. 264, no. 3, pp. 145-154, 2009.

[3] J. D. Blair, M. G. Ikonomou, B. C. Kelly, B. Surridge, and F. A. P. C. Gobas, "Ultra-trace determination of phthalate ester metabolites in seawater, sediments, and biota from an urbanized marine inlet by LC/ESI-MS/MS," Environmental Science and Technology, vol. 43, no. 16, pp. 6262-6268, 2009.

[4] A. M. Calafat, A. R. Slakman, M. J. Silva, A. R. Herbert, and L. L. Needham, "Automated solid phase extraction and quantitative analysis of human milk for 13 phthalate metabolites," Journal of Chromatography B, vol. 805, no. 1, pp. 49-56, 2004.

[5] S. Jonsson, J. Ejlertsson, A. Ledin, I. Mersiowsky, and B. H. Svensson, "Mono- and diesters from o-phthalic acid in leachates from different European landfills," Water Research, vol. 37, no. 3, pp. 609-617, 2003.

[6] S. Jonsson, J. Ejlertsson, and B. H. Svensson, "Behaviour of mono- and diesters of o-phthalic acid in leachates released during digestion of municipal solid waste under landfill conditions," Advances in Environmental Research, vol. 7, no. 2, pp. 429-440, 2003.

[7] S. V. Otton, S. Sura, J. Blair, M. G. Ikonomou, and F. A. P. C. Gobas, "Biodegradation of mono-alkyl phthalate esters in natural sediments," Chemosphere, vol. 71, no. 11, pp. 2011-2016, 2008.

[8] B. V. Chang, Y. S. Lu, S. Y. Yuan, T. M. Tsao, and M. K. Wang, "Biodegradation of phthalate esters in compost-amended soil," Chemosphere, vol. 74, no. 6, pp. 873-877, 2009.

[9] H. Liu, D. Zhang, M. J. Li, L. Tong, and L. Feng, "Competitive adsorption and transport of phthalate esters in the clay layer of JiangHan plain, China," Chemosphere, vol. 92, no. 11, pp. 15421549, 2013.

[10] J. Catherine, S. H. Liu, and J. F. Kennedy, "Comparative study of the adsorption on chitosan beads of phthalate esters and their degradation products," Carbohydrate Polymers, vol. 81, no. 3, pp. 640-644, 2010.

[11] T. T. H. Pham, R. D. Tyagi, S. K. Brar, and R. Y. Surampalli, "Effect of ultrasonication and Fenton oxidation on biodegradation of bis(2-ethylhexyl) phthalate (DEHP) in wastewater sludge," Chemosphere, vol. 82, no. 6, pp. 923-928, 2011.

[12] S. Chatterjee and T. K. Dutta, "Metabolism of butyl benzyl phthalate by Gordonia sp. strain MTCC 4818," Biochemical and Biophysical Research Communications, vol. 309, no. 1, pp. 36-43, 2003.

[13] T. Saito, P. Hong, R. Tanabe, K. Nagai, and K. Kato, "Enzymatic hydrolysis of structurally diverse phthalic acid esters by porcine and bovine pancreatic cholesterol esterases," Chemosphere, vol. 81, no. 11, pp. 1544-1548, 2010.

[14] B. C. Pan, Q. X. Zhang, F. W. Meng et al., "Sorption enhancement of aromatic sulfonates onto an animated hyper-crosslinked polymer," Environmental Science and Technology, vol. 39, no. 9, pp. 3308-3313, 2005.

[15] Z. W. Xu, W. Z. Zhang, L. Lv, B. C. Pan, P. Lan, and Q. Zhang, "A new approach to catalytic degradation of dimethyl phthlate by a macroporous $\mathrm{OH}$-type strongly basic anion exchange resin," Environmental Science and Technology, vol. 44, no. 8, pp. 31303135, 2010.

[16] K. Kato, M. J. Silva, L. L. Needham, and A. M. Calafat, "Determination of total phthalates in urine by isotope-dilution liquid chromatography-tandem mass spectrometry," Journal of Chromatography B, vol. 814, no. 2, pp. 355-360, 2005.

[17] B. Von Oepen, W. Kordel, and W. Klein, "Sorption of nonpolar and polar compounds to soils: processes, measurements and experience with the applicability of the modified OECDGuideline 106," Chemosphere, vol. 22, no. 3-4, pp. 285-304, 1991.

[18] J. L. Wang, L. J. Chen, C. Shi, and Q. Yi, "Microbial degradation of phthalic acid esters under anaerobic digestion of sludge," Chemosphere, vol. 41, no. 8, pp. 1245-1248, 2000.

[19] Q. J. Zhang, Z. W. Xu, K. Zheng et al., "Adsorption behavior of pnitroaniline on macroporous polymer and its application," Ion Exchange and Adsorption, vol. 22, no. 6, pp. 503-511, 2006.

[20] Y. Liu, "Is the free energy change of adsorption correctly calculated?" Journal of Chemical and Engineering Data, vol. 54, no. 7, pp. 1981-1985, 2009.

[21] C. H. Wu, "Studies of the equilibrium and thermodynamics of the adsorption of $\mathrm{Cu}^{2+}$ onto as-produced and modified carbon nanotubes," Journal of Colloid and Interface Science, vol. 311, no. 2, pp. 338-346, 2007.

[22] S. Shrestha, G. Son, S. H. Lee, and T. G. Lee, "Isotherm and thermodynamic studies of $\mathrm{Zn}$ (II) adsorption on lignite and coconut shell-based activated carbon fiber," Chemosphere, vol. 92, no. 8, pp. 1053-1106, 2013.

[23] D. M. Nevskaia, A. Santianes, V. Muñoz, and A. Guerrero-Ruíz, "Interaction of aqueous solutions of phenol with commercial activated carbons: an adsorption and kinetic study," Carbon, vol. 37, no. 7, pp. 1065-1074, 1999. 

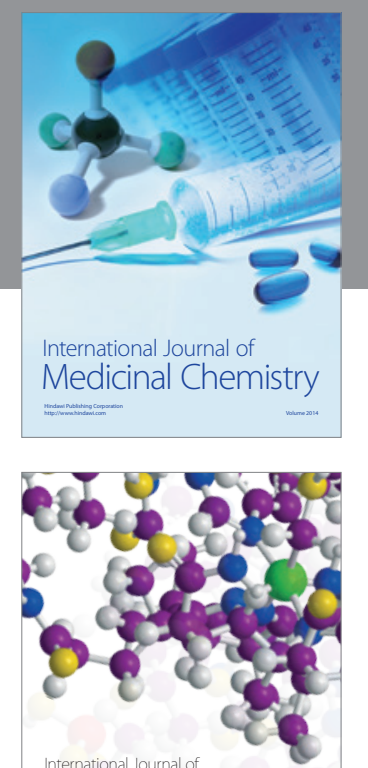

\section{Carbohydrate} Chemistry

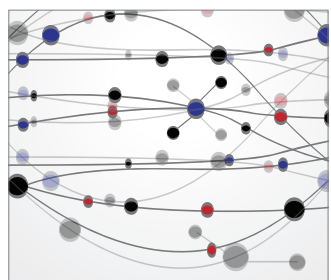

The Scientific World Journal
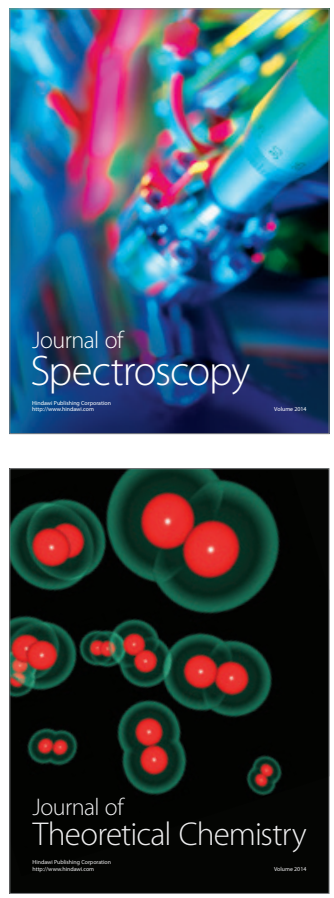
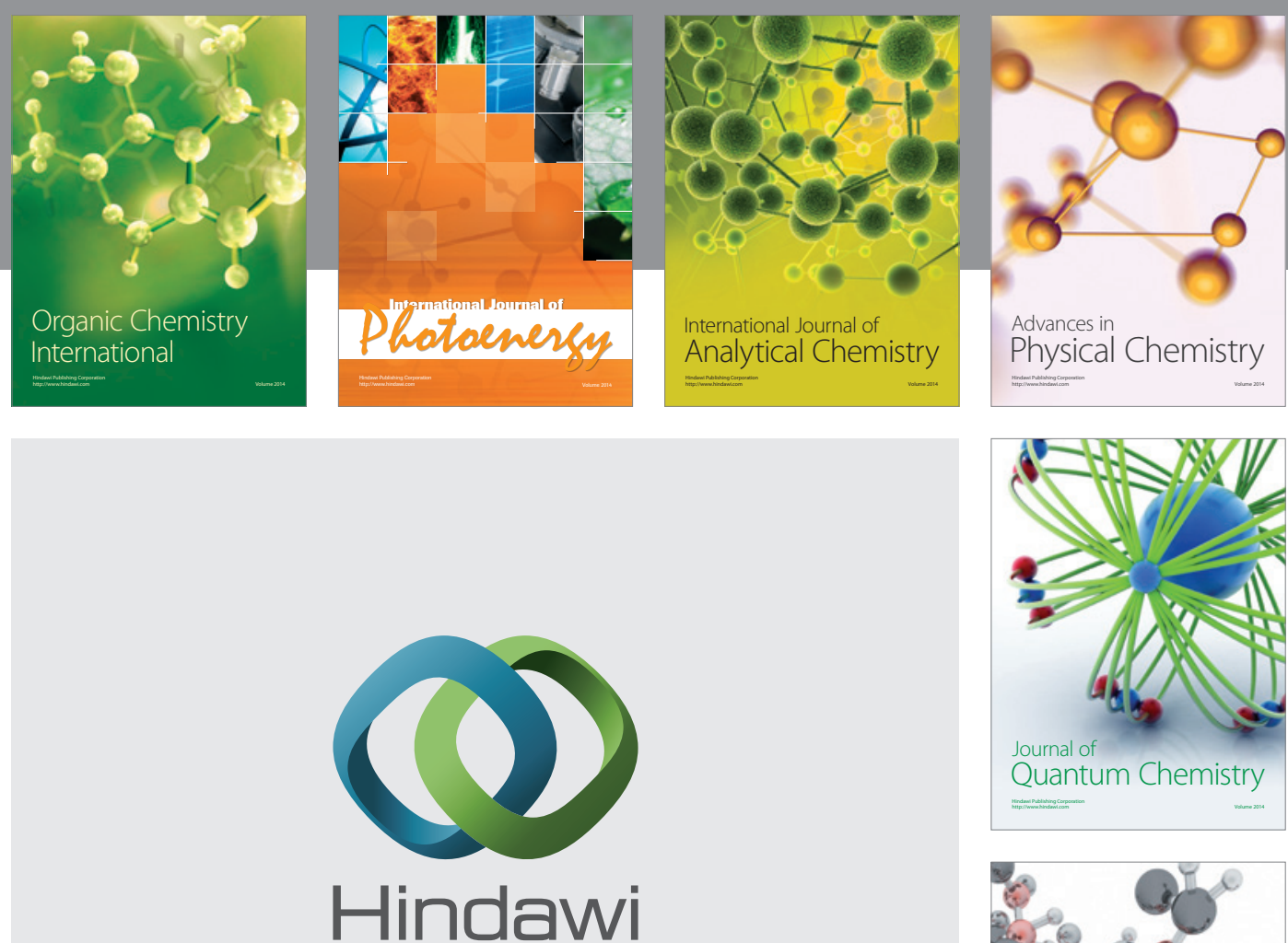

Submit your manuscripts at

http://www.hindawi.com

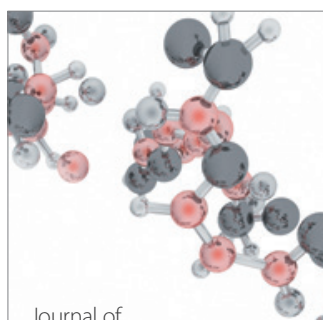

Analytical Methods

in Chemistry

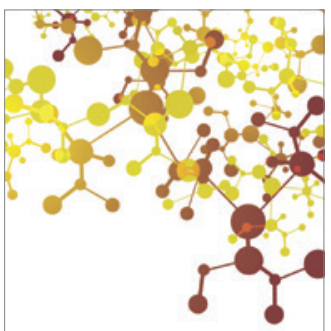

Journal of

Applied Chemistry

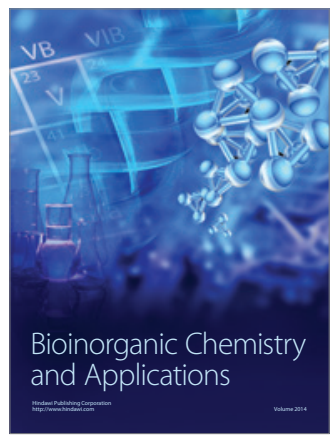

Inorganic Chemistry
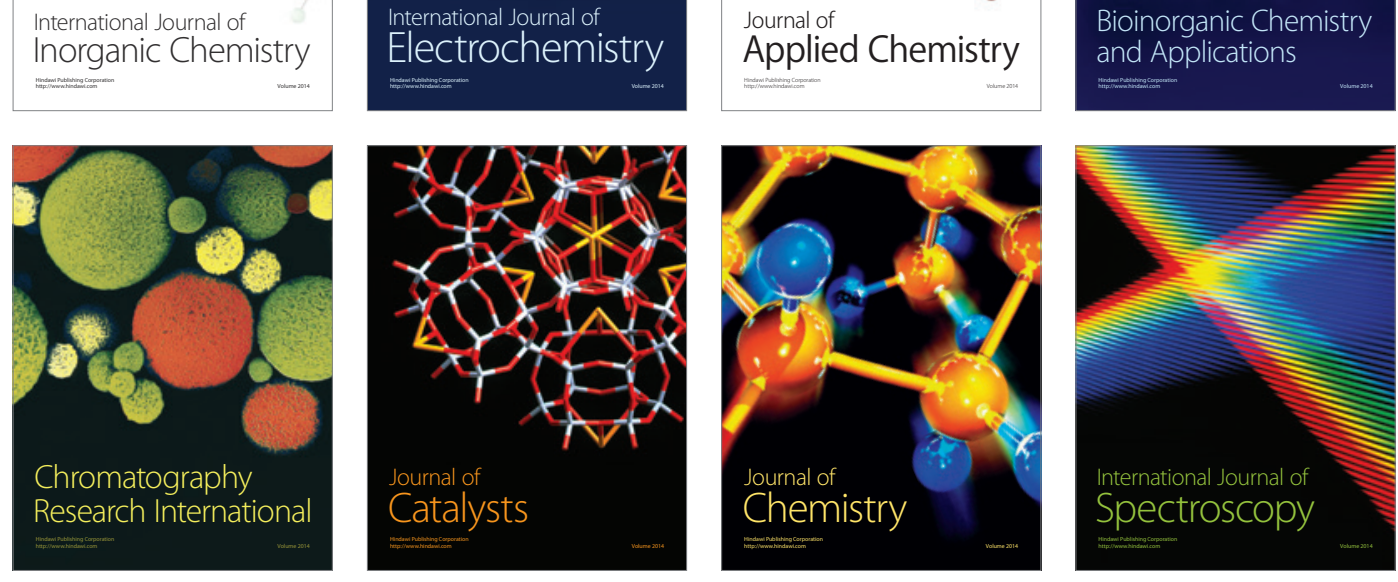